\title{
ULTRAVIOLET SPECTROSCOPY AND ITS PHARMACEUTICAL APPLICATIONS- A BRIEF REVIEW
}

\author{
DIPALI M ATOLE*, HRISHIKESH H RAJPUT
}

Department of Pharmaceutics, Government College of Pharmacy, Aurangabad, Maharashtra, India. Email: dipaliatole123@gmail.com

Received: 14 July 2017, Revised and Accepted: 21 November 2017

\begin{abstract}
Rapid and easy analytical methods are needed due to increasing number of multicomponent formulations, biotherapeutic products and samples of complex matrix in que. Number of Ultraviolet (UV) spectrophotometric methods used for these purpose. Different types of UV spectrometric methods developed on the basis of principle of additivity, absorbance difference, processing absorption spectra. The aim of this review is to present information on simultaneous equation method, difference spectrophotometry, derivative spectrophotometry, absorbance ratio spectra, derivative ratio spectra, successive ratio - derivative spectra, Q-absorbance ratio method, absorptivity factor method, dual wavelength method, absorption factor method, multivariate chemometric methods, and isosbestic point method. A brief summary on theories, mathematical background and some applications of these methods are presented here.
\end{abstract}

Keywords: Ultraviolet spectroscopy, Simultaneous equation method, Derivative spectrophotometry, Derivative ratio spectra, Isosbestic point method, Multivariate chemometric methods.

(C) 2018 The Authors. Published by Innovare Academic Sciences Pvt Ltd. This is an open access article under the CC BY license (http://creativecommons. org/licenses/by/4. 0/) DOI: http://dx.doi.org/10.22159/ajpcr.2018.v11i2.21361

\section{INTRODUCTION}

In routine practice, analyst has to perform rapid analysis of multicomponent formulations, biotherapeutic products and samples of a complex matrix. Number of ultraviolet (UV) spectrophotometric methods used for these purpose. However, among all of these methods, UV spectrophotometry is favorite tool. The basic principle behind the UV spectroscopy is absorption of visible and UV radiation (200$400 \mathrm{~nm}$ ) is associated with excitation of electrons, in both atoms and molecules, from lower to higher energy levels. Since the energy levels of matter are quantized, only light with the precise amount of energy can cause transitions from one level to another will be absorbed [1]. UV spectrophotometric methods based on principle of additivity and absorbance, recording and mathematical processing absorption spectra of standard solutions and sample solutions in same way or differently.

\section{TYPES OF UV SPECTROSCOPIC ANALYTICAL TECHNIQUES}

Following are the different UV spectroscopic analytical techniques: Simultaneous equation method, difference spectrophotometry, derivative spectrophotometry, absorbance ratio spectra, derivative ratio spectra, successive ratio - derivative spectra, Q-absorbance ratio method, absorptivity factor method, dual wavelength method, absorption factor method, multivariate chemometric methods, and isosbestic point method.

\section{Simultaneous equation method}

Simultaneous equation method is useful to determine drugs which absorb at the $\lambda_{\max }$ of other in the binary or ternary mixture.

\section{Consider}

- The absorptivities of $\mathrm{X}$ at $\lambda_{1}$ and $\lambda_{2}, \mathrm{a}_{\mathrm{x} 1}$ and $\mathrm{a}_{\mathrm{x} 2}$, respectively

- The absorptivities of $Y$ at $\lambda_{1}$ and $\lambda_{2}, a_{y 1}$ and $a_{y 2}$, respectively

- The absorbance of the dilute sample at $\lambda_{1}$ and $\lambda_{2}, A_{1}$ and $A_{2}$, respectively

- $\mathrm{X}$, have concentration $\mathrm{c}_{\mathrm{x}}$ and $\mathrm{Y}$ have concentration $\mathrm{c}_{\mathrm{y}}$ in dilute sample

According to the fact, the concentration of mixture is the sum of the individual concentrations of $\mathrm{X}$ and $\mathrm{Y}$.
So, at $\lambda_{1} A_{1}=a_{x 1} b c_{x}+a_{y 1} b c_{y}$

At $\lambda_{2} A_{2}=a_{x 2} b c_{x}+a_{y 2} b c_{y}$

If cell is $1 \mathrm{~cm}, \mathrm{~b}=1$ equation 2 become,

$c_{y}=\left(A-a_{x 2} c_{x}\right) / a_{y 2}$

Substituting value of cy in equation (1), thus

$a_{x 1} b c_{x}=A-a_{y 1} c_{y}$

$c_{x}=\left(A_{2} a_{y 1}-A_{1} a_{y 2}\right) /\left(a_{x 2} a_{y 1}-a_{x 1} a_{y 2}\right)$

Similarly for $\mathrm{c}_{\mathrm{y}}$

$c_{y}=\left(A_{1} a_{x 2}-A_{2} a_{x 1}\right) /\left(a_{x 2} a_{y 1}-a_{x 1} a_{y 2}\right)$

"Glenn" have been suggested criteria for obtaining maximum precision, based on absorbance ratio that place limit on the relative concentration of the component of the mixture. The criteria for that ratio should lie outside the range $0.1-2$ for precise determination of $\mathrm{X}$ and $\mathrm{Y}$, respectively.

Condition to fulfill this criteria:

- $\lambda_{\max }$ of two-component should be reasonably dissimilar.

- Two-component should not interact chemically, thereby negating the initial assumption that the absorbance.

The additivity of the absorbance should always be confirmed in the development of a new application of this technique. Table 1 summarizes the application of simultaneous equation method for determination of binary mixture in the pharmaceutical dosage form and Table 2 summarizes the application of simultaneous equation method for determination of ternary mixture in the pharmaceutical dosage form.

\section{Difference spectrophotometry}

It is a spectrophotometric technique for quantitative determination of an analyte using an equimolar solution of the same analyte as a reference but in the different physicochemical environment, by virtue 
of their differences in spectral properties [10]. In this spectroscopic technique, isolation of an analyte from another component of mixture or other UV active analyte present in mixture sample is achieved. Physicochemical conditions altered mainly involve changes in $\mathrm{pH}$ [11], temperature [12].

The requirement of technique is that the analyte under investigation must exist in different chemical forms having different absorbance values. The value is calculated in terms of absorbance difference (amplitude difference in maxima and minima) and plotted versus the concentration of solution examined. Both the selectivity and specificity of analytical method improves by difference spectroscopy, since difference spectra of dosage form overlapped on the pure drug without the presence of interfering peaks due to excipients involved in the dosage form. Table 3 summarizes the applications of difference spectroscopy to drug substance in dosage forms.

Difference spectroscopy used in simultaneous determinations of many dosage forms. In case of binary mixtures determination, wavelength selected such that the contribution of each component is zero at the wavelength at which other components exhibited maximum absorbance. Table 4 summarizes some examples of pharmaceutical applications of difference spectroscopy involving binary mixtures.

Apart from pharmaceutical assay, difference spectroscopy also used in biopharmaceutical formulation development to characterize protein structure and to investigate the response of structure to the formulation composition. This application based on the fact that stable protein conformations provide high real-time physical stability and difference spectra used for characterizing and quantifying changes in protein structure [17].

Moschakis and Nikolaidis, done denaturation study of BSA, by investigating protein conformational changes induced either by heat. The spectra of the heat-treated samples were subtracted from that of the unheated protein solution. For the difference spectra of protein solutions in $\mathrm{GdHCl}$ or urea, the spectrum of $0.2 \%(\mathrm{w} / \mathrm{w})$ BSA solutions in $\mathrm{GdHCl}$ (or urea) against the solvent ( $\mathrm{GdHCl}$ or urea solution of the same molarity) in the reference cuvette was subtracted from the spectrum of the protein solution against double distilled water in the reference cuvette (untreated protein solution) [12].

\section{Derivative spectrophotometry}

Derivative spectroscopy, as per name indicates, involves derivative of absorbance of zero order or simple absorption spectrum with respect to wavelength. Derivative spectroscopy follows principle additivity, and absorbance is also dependence on concentration [18].

Nowadays derivative spectra obtained directly from spectrophotometers enabled with advanced software such as UV-probe. These software eliminate the need for additional mathematical process or changes in instrumental parameters. Previously derivative spectra were generated by optical method (wavelength modulation technique) [19] and electrical method (analog resistance capacitance device) [18]. Later in

Table 1: Application of simultaneous equation method for determination of binary mixture in pharmaceutical dosage form

\begin{tabular}{|c|c|c|c|}
\hline Drug & Spectroscopic condition ( $\lambda \max$ and solvent) & Beer's law range $\mu \mathrm{g} \backslash \mathbf{m l}$ & Reference \\
\hline Rabeprazole sodium and levosulpiride & $284 \mathrm{~nm}, 232 \mathrm{~nm}$ methanol & $1-20$ and $1-20$ & {$[2]$} \\
\hline Ofloxacin and ornidazole & $240.6 \mathrm{~nm}, 279.4 \mathrm{~nm}$ methanol & $20-40$ and $16-32$ & [3] \\
\hline Norfloxacin and tinidazole & $273 \mathrm{~nm}, 319 \mathrm{~nm}$ methanol & $2.5-20$ and $5-40$ & [4] \\
\hline Paracetamol and diclofenac sodium & 247 nm, 276 nm water & $5-35$ and $5-40$ & [5] \\
\hline
\end{tabular}

Table 2: Application of simultaneous equation method for determination of ternary mixture in pharmaceutical dosage form

\begin{tabular}{|c|c|c|c|}
\hline Drug & Spectroscopic condition $\lambda \max$ (solvent) & $\begin{array}{l}\text { Beer's law } \\
\text { range } \mu \mathrm{g} \backslash \mathbf{m l}\end{array}$ & References \\
\hline Tenofovir, efavirenz, and lamivudine & $260 \mathrm{~nm}, 347 \mathrm{~nm}, 272 \mathrm{~nm}$ (methanol) & $\begin{array}{l}10-60 \\
5-30 \\
5-30\end{array}$ & [6] \\
\hline $\begin{array}{l}\text { Amlodipine besylate, losartan potassium, and } \\
\text { hydrochlorothiazide }\end{array}$ & $236.5 \mathrm{~nm}, 254 \mathrm{~nm}, 271 \mathrm{~nm}$ (methanol) & $\begin{array}{l}5-25 \\
10-50 \\
5-25\end{array}$ & [7] \\
\hline Amlodipine besylate, valsartan, and hydrochlorothiazide & $359 \mathrm{~nm}, 250 \mathrm{~nm}, 317 \mathrm{~nm}$ (methanol) & $\begin{array}{l}5-25 \\
5-25 \\
10-50\end{array}$ & [8] \\
\hline Quercetin, curcumin, and piperine & $\begin{array}{l}371.31 \mathrm{~nm}, 424.68 \mathrm{~nm}, 343.76 \\
\mathrm{~nm} \text { (methanol) }\end{array}$ & $\begin{array}{l}5-30 \\
1-5 \\
1-10\end{array}$ & [9] \\
\hline
\end{tabular}

Table 3: Applications of difference spectroscopy to drug substance in dosage forms

\begin{tabular}{llll}
\hline Drug & Solvent conditions used & Wavelength of maxima and minima & References \\
\hline Leflunomide & $\mathrm{NaOH}(0.1 \mathrm{M})$ and $\mathrm{HCl}(0.1 \mathrm{M})$ & $293.5 \mathrm{~nm}$ and $261.5 \mathrm{~nm}$ & {$[13]$} \\
Tegaserod maleate & $\mathrm{NaOH}(0.1 \mathrm{M})$ and $\mathrm{HCl}(0.1 \mathrm{M})$ & $226 \mathrm{~nm}$ and $256 \mathrm{~nm}$ & {$[14]$} \\
\hline
\end{tabular}

Table 4: Some examples of pharmaceutical applications of difference spectroscopy involving binary mixtures

\begin{tabular}{llll}
\hline Drug & Solvent conditions used & $\begin{array}{l}\text { Wavelength of zero } \\
\text { crossing }\end{array}$ & References \\
\hline Pioglitazone and metformin & phosphate buffer $(\mathrm{pH} 9)$ and chloride buffer $(\mathrm{pH} 2)$ & $228.1 \mathrm{~nm}$ and $228.2 \mathrm{~nm}$ & {$[15]$} \\
Olmesartanand hydrochlorothiazide & $\mathrm{NaOH}(0.1 \mathrm{M})$ and $\mathrm{HCl}(0.1 \mathrm{M})$ & $257.8 \mathrm{~nm}$ and $240.2 \mathrm{~nm}$ & {$[16]$} \\
\hline
\end{tabular}


1974, new mathematical technique was introduced named as Golaysavitzky method [20] which became commercially popular and part of software now.

Derivative spectroscopy used to analyze wide variety and complex origin such as pharmaceutical dosage forms, inorganic samples with metal content biological samples, and samples of food content [21].

Derivative spectroscopy offers following advantages [22,23]:

1. Resolve overlapping peaks of complex samples such as ternary mixture

2. Improve spectral quality by eliminating baseline shift and scattering

3. Direct UV-analysis of samples of complex origin without any chemical pre-treatment of sample of biological origin

4. Allows analysis at lower sample content impurity profiling.

From analytical method point of view, both sensitivity and selectivity of analytical method is improved.

Zero order equation $\mathrm{A}=\mathrm{abc}$

First order equation $\frac{\mathrm{dA}}{\mathrm{d} \lambda}=\frac{\mathrm{da}}{\mathrm{d} \lambda} \mathrm{bc}$

$\mathrm{n}^{\text {th }}$ order equation $\frac{\mathrm{dnA}}{\mathrm{d} \lambda \mathrm{n}}=\frac{\mathrm{dna}}{\mathrm{d} \lambda \mathrm{n}} \mathrm{bc}$

Derivative spectra magnify the information content from fundamental zero order spectra and are complicated comparatively. Table 5 summarizes the spectral feature of different order derivative spectra.

Measurement technique in derivative spectroscopy: Zero crossing technique and peak to through technique [20]. However for pharmaceutical analysis purpose zero crossing technique is most favorite tool. Zero crossing technique is based on the fact that in derivative spectra absorbance of one component shows no absorbance at such instance absorbance of sample is equal to that of other component in sample which can be used to find its concentration. Table 6 summarizes the applications of zero crossing technique to analysis of binary mixtures and Table 7 applications of zero crossing technique to analysis of ternary mixtures.

Apart from pharmaceutical assay derivative spectroscopy also finds its application in a clinical study such as quantitative assay of diazepam in human blood plasma without separation of the drug from the biological matrix [20].

Furthermore, derivative spectroscopy had been used for stability study purpose. Using the second derivative UV spectrophotometry, butamirate citrate, and formoterol fumarate were determined by measuring the peak amplitude at 260.4 and $261.8 \mathrm{~nm}$, respectively, without any interference of their degradation products [33].

With derivatization of spectra, signal-to-noise ratio increases. Furthermore, reproducibility obtained with derivative spectroscopy is very low. Anatov et al. reported method of step-by-step-filter method to improve the signal to noise ratio [34]. Brown et al. reported method of derivative reprocessing where drift noise reduction achieved for multivariate spectral data [35]. Apart from above-mentioned methodology, few variants of derivative spectroscopy were reported globally. Wavelet transformation technique employed successfully for derivative spectroscopy too [36].

\section{Ratio derivative spectroscopy}

Spectrophotometric determination of two or more compounds in the same sample without preliminary separation is in demand. In past decade ratio derivative spectroscopy emerged as good tool to serve this purpose which was based on work of Salinas et al., where they developed a spectrophotometric method based on the use of the first derivative of the ratio spectra for resolving binary mixtures when the spectra of the components are overlapped. It permits the use of the wavelength of the highest value of analytical signals with several peaks and trough, which permits the determination of an analyte in the presence of other compounds and excipients which could possibly interfere in the analysis [37].

The method involves following steps

- Recording mixture spectra of samples under investigation.

- Dividing the mixture spectra by a standard divisor spectrum.

- Followed by peak-to-peak/peak-to-trough measurement in the produced ratio spectra, which directly gives the concentration of one of the component in mixture.

The method eliminates the derivative step and does not require searching for zero-crossing points or any sophisticated mathematical or chemometric treatment of data.

${ }_{\lambda 1} \mathrm{~A}_{\mathrm{M}}={ }_{\lambda 1} \mathrm{E}_{\mathrm{A}} \mathrm{C}_{\mathrm{A}}+{ }_{\lambda 1} \mathrm{E}_{\mathrm{B}} \mathrm{C}_{\mathrm{B}}$

Table 5: Spectral feature of different order derivative spectra [18]

\begin{tabular}{ll}
\hline $\begin{array}{l}\text { Derivative } \\
\text { order }\end{array}$ & Spectral feature \\
\hline First order & $\begin{array}{l}\text { First order derivative spectra start and finish at zero. It also passes through zero at the same wavelength as } \lambda_{\text {max }} \text { of the } \\
\text { absorbance band of zero order spectra, at an inflection point. Either side of this point possesses positive and negative bands with } \\
\text { maxima and minima }\end{array}$ \\
$\begin{array}{l}\text { Second order } \\
\text { Third order }\end{array}$ & $\begin{array}{l}\text { Similar to first order derivative spectra it also possesses inflection point at } \lambda_{\text {max }} \text { of the absorbance band of zero order spectra. } \\
\text { Along with positive and negative satellite bands on either side of minima and maxima, respectively }\end{array}$ \\
Fourth order & Main extreme maxima appear at $\lambda_{\max }$ of the absorbance band, along with two negative satellite bands on its either side \\
\hline
\end{tabular}

Table 6: Applications of zero crossing technique to analysis of binary mixtures

\begin{tabular}{llll}
\hline Drug & Order of dvt spectra & Wavelength of zero crossing & References \\
\hline Imipenem and cilastatin & 1 & 243 and $300 \mathrm{~nm}$ \\
Gatifloxacin and prednisolone & 1 & 348 and 263 $\mathrm{nm}$ & {$[24]$} \\
Ofloxacin and ornidazole & 1 & 278 and 293.6 $\mathrm{nm}$ \\
Ezetimibe and lovastatin & 1 & $265.20 \mathrm{and} 245.4 \mathrm{~nm}$ \\
Ofloxacin and cefixime & 1 & $282.8 \mathrm{and} 318.6 \mathrm{~nm}$ \\
Rosuvastatin Ca and fenofibrate & 1 & 243 and 224 $\mathrm{nm}$ & {$[26]$} \\
Salbutamol sulfate and ketotifen fumarate & 1 & 257 and 278 $\mathrm{nm}$ \\
\hline
\end{tabular}


${ }_{\lambda 1} A_{M}$-absorbance of mixture.

${ }_{\lambda 1} E_{A}$ and ${ }_{\lambda 1} E_{B}-$ molar absorptivities of $A$ and $B$.

$\mathrm{C}_{\mathrm{A}}$ and $\mathrm{C}_{\mathrm{B}}$ - concentration of $\mathrm{A}$ and $\mathrm{B}$ in mixture.

Above equation (8) is divided by the absorbance of a standard solution of $A$ at $\lambda 1$ whose concentration is $C_{A^{\prime}}^{\circ}$, then equation becomes,

$$
\frac{\lambda 1 \mathrm{~A}_{\mathrm{M}}}{{ }_{\lambda 1} \mathrm{E}_{\mathrm{A}} \mathrm{CR}_{\mathrm{A}}}=\frac{\mathrm{C}_{\mathrm{A}}}{\mathrm{CR}_{\mathrm{A}}}+\frac{{ }_{\lambda 1} \mathrm{E}_{\mathrm{B}} \mathrm{C}_{\mathrm{B}}}{{ }_{\lambda 1} \mathrm{E}_{\mathrm{A}} \mathrm{CR}_{\mathrm{A}}}
$$

This equation can be simplified to

$$
\frac{{ }_{\lambda 1} \mathrm{~A}_{\mathrm{A}}}{\lambda_{11} \mathrm{E}_{\mathrm{A}}}=\frac{\mathrm{C}_{\mathrm{A}}+{ }_{\lambda 1} \mathrm{E}_{\mathrm{B}} \mathrm{C}_{\mathrm{B}}}{\lambda_{1} \mathrm{E}_{\mathrm{A}}}
$$

By plotting ${ }_{\lambda 1} \mathrm{~A}_{\mathrm{M} / \lambda 1} \mathrm{E}_{\mathrm{A}}$ as a function of $\mathrm{E}_{\mathrm{B}} / \mathrm{E}_{\mathrm{A}^{\prime}}$ a straight line is obtained.

The intercept of the straight line provides the value of $\mathrm{C}_{\mathrm{A}^{\prime}}$ and the slope of the straight line is $C_{B}$. To obtain the ratio $E_{B} / E_{A}$ at each wavelength, the absorption spectra of equimolar standard solutions of $\mathrm{B}$ and $\mathrm{A}$ are measured, and the absorbance ratio at each wavelength is calculated. Table 8 summarizes the application of ratio derivative spectroscopy to pharmaceutical dosage forms.

\section{Successive ratio derivative spectra method}

This method is used for determination of drugs in the ternary mixture without information of ratio of drugs concentration in the mixture [42]. Consider a mixture of three drugs X, Y, and Z following Beer's law is obeyed in the whole wavelength range used and by considering the path length as $1 \mathrm{~cm}$, the total absorbance of the ternary mixture at each wavelength can be written as:

$\mathrm{A}_{\mathrm{m}}=\alpha_{\mathrm{x}} \mathrm{C}_{\mathrm{x}}+\alpha_{\mathrm{y}} \mathrm{C}_{\mathrm{y}}+\alpha_{\mathrm{z}} \mathrm{C}_{\mathrm{z}}$

Where $A_{m}$ is the total absorbance of the mixture, $\alpha_{y^{\prime}} \alpha_{y}$, and $\alpha_{z}$ are the absorptivity values of $\mathrm{X}, \mathrm{Y}$ and $\mathrm{Z}$ and $\mathrm{C}_{\mathrm{x}^{\prime}} \mathrm{C}_{\mathrm{y}^{\prime}}$ and $\mathrm{C}_{\mathrm{z}}$ are the concentrations of $\mathrm{X}, \mathrm{Y}$, and $\mathrm{Z}$, respectively.

If equation 10 is divided by $\alpha_{z}$ corresponding to the spectrum of a standard solution of $\mathrm{Z}$ in ternary mixture, the first ratio spectrum is obtained in the form of equation (11) (for possibility of dividing operation, the zero values of $\alpha \mathrm{Z}$ should not be used in the divisor):

\section{Table 7: Applications of zero crossing technique to analysis of}

\begin{tabular}{|c|c|c|c|}
\hline Drug & $\begin{array}{l}\text { Order of } \\
\text { dvt spectra }\end{array}$ & $\begin{array}{l}\text { Wavelength of } \\
\text { zero crossing }\end{array}$ & References \\
\hline \multirow{2}{*}{$\begin{array}{l}\text { Amiloride, } \\
\text { hydrochlorothiazide } \\
\text { salbutamol sulfate, } \\
\text { bromhexine } \\
\text { hydrochloride, and } \\
\text { etofylline }\end{array}$} & $1,3,1$ & $\begin{array}{l}365 \mathrm{~nm}, 265 \mathrm{~nm} \\
\text { and } 385 \mathrm{~nm}\end{array}$ & [31] \\
\hline & $1,1,1$ & $\begin{array}{l}273 \mathrm{~nm}, 323 \mathrm{~nm} \\
\text { and } 279 \mathrm{~nm}\end{array}$ & [32] \\
\hline
\end{tabular}
ternary mixtures
$\mathrm{B}=\mathrm{A}_{\mathrm{m}} / \alpha_{\mathrm{z}}=\alpha_{\mathrm{x}} \mathrm{C}_{\mathrm{x}} / \alpha_{\mathrm{z}}+\alpha_{\mathrm{y}} \mathrm{C}_{\mathrm{y}} / \alpha_{\mathrm{z}}+\mathrm{C}_{\mathrm{z}}$

If the first derivative of equation (11) is taken since the derivative of a constant $\left(\mathrm{C}_{\mathrm{z}}\right)$ is zero, first derivative ratio spectra would be obtainedin the form of equation (12):

$\mathrm{dB} / \mathrm{d} \lambda=\mathrm{d} / \mathrm{d} \lambda\left(\alpha_{\mathrm{x}} \mathrm{C}_{\mathrm{x}} / \alpha_{\mathrm{z}}\right)+\mathrm{d} / \mathrm{d} \lambda\left(\alpha_{\mathrm{y}} \mathrm{C}_{\mathrm{y}} / \alpha_{\mathrm{z}}\right)$

Dividing equation (6) by $d / d \lambda(\alpha Y / \alpha Z$ ), corresponding to the derivative of the ratio of the spectra of the standard solutions of $\mathrm{Y}$ and $\mathrm{Z}$, the second ratio spectrum is obtained as equation (13)

(for possibility of dividing operation, the zero values of $(d / d \lambda)(\alpha Y / \alpha Z)$ should not be used in the divisor):

$\mathrm{D}=(\mathrm{dB} / \mathrm{d} \lambda) / \mathrm{d} / \mathrm{d} \lambda(\alpha \mathrm{Y} / \alpha \mathrm{Z})=\mathrm{d} / \mathrm{d} \lambda[\alpha \mathrm{XCX} / \alpha \mathrm{Z}] / \mathrm{d} / \mathrm{d} \lambda(\alpha \mathrm{Y} / \alpha \mathrm{Z})+\mathrm{CY}$

If the first derivative of equation (13) is taken since the derivative of a constant $\left(\mathrm{C}_{\mathrm{Y}}\right)$ is zero,

Equation (14) would be obtained:

$\mathrm{dD} / \mathrm{d} \lambda=\mathrm{d} / \mathrm{d} \lambda\{[\mathrm{d} / \mathrm{d} \lambda(\alpha \mathrm{XCX} / \alpha \mathrm{Z})] /[(\mathrm{d} / \mathrm{d} \lambda(\alpha \mathrm{Y} / \alpha \mathrm{Z})]\}$

Equation (14) is the mathematical foundation of multicomponent analysis that permits the determination of the concentration of each of the active drugs in the solution ( $\mathrm{X}$ in this equation) without interference from the other drugs of the ternary system ( $\mathrm{Y}$ and $\mathrm{Z}$ in these equations). As equation (14) shows, there is a linear relationship between the amount of $\mathrm{dD} / \mathrm{d} \lambda$ and the concentration of $\mathrm{X}$ in the solution. A calibration curve could be constructed by plotting $\mathrm{dD} / \mathrm{d} \lambda$ against the concentration of $\mathrm{X}$ in the standard solutions of $\mathrm{X}$ or in the standard ternary mixtures.

For more sensitivity, the amount of $\mathrm{dD} / \mathrm{d} \lambda$ corresponding to maximum or minimum wavelength should be measured. Calibration graphs for $\mathrm{Y}$ and $\mathrm{Z}$ could be also constructed as described for $\mathrm{X}$.

Abdelrahman and Abdelaleem applied successive ratio spectra method to pharmaceutical ternary mixtures including isopropamide iodide, trifluoperazine hydrochloride, and trifluoperazine oxidative degradate [42].

\section{Q-absorbance ratio method}

The method is applicable only when beers law is followed for a given combination of the drug. This method is based on the fact that the ratio of absorbance at any two wavelengths for a substance, which obeys Beer's law, is a constant value independent of the concentration and path length. This constant is termed as "Hufner's Quotient" or Q-value. The Q-absorbance equation formed using the absorptivity values at two wavelengths used as such, one being the $\lambda_{\max }$ of one of the components and the other being a wavelength of isoabsorptive point $[43,44]$. Table 9 summarizes the applications of $Q$ absorbance ratio method.

The absorbance and absorptivity values at the particular wavelengths were calculated and substituted in the following equation; to obtain the concentration.

\begin{tabular}{|c|c|c|}
\hline Drug & Wavelength of determinations & References \\
\hline Rabeprazole sodium and itopride hydrochloride & $231 \mathrm{~nm}$ (rabeprazole sodium) and $260 \mathrm{~nm}$ (itopride hydrochloride) & [38] \\
\hline Naphazoline and antazoline & $227.2 \mathrm{~nm}$ (naphazoline) and $235 \mathrm{~nm}$ (antazoline) & [39] \\
\hline Paracetamol and aceclofenac & $256 \mathrm{~nm}$ (paracetamol) and $268 \mathrm{~nm}$ (aceclofenac) & [38] \\
\hline $\begin{array}{l}\text { Salbutamol sulfate, bromhexine hydrochloride, and } \\
\text { etofylline }\end{array}$ & $\begin{array}{l}247.8 \mathrm{~nm} \text { (salbutamol sulfate) } 248.6 \mathrm{~nm} \text { (bromhexine hydrochloride), } \\
276.8 \mathrm{~nm} \text { (etofylline) }\end{array}$ & [32] \\
\hline Diflucortolone valerate and isoconazole nitrate & $241.1 \mathrm{~nm}$ (diflucortolone valerate) and $279.8 \mathrm{~nm}$ (isoconazole nitrate) & {$[40]$} \\
\hline Gabapentin, methylcobalamin and alpha lipoic acid & $\begin{array}{l}731.10 \mathrm{~nm} \text { (gabapentin), } 768.53 \mathrm{~nm} \text { (methylcobalamin), and } 242.21 \\
\mathrm{~nm} \text { (alpha lipoic acid) }\end{array}$ & {$[41]$} \\
\hline
\end{tabular}

Table 8: Application of ratio derivative spectroscopy to pharmaceutical dosage forms 
Table 9: Illustrates the applications of $Q$ absorbance ratio method

\begin{tabular}{lll}
\hline Drug & Wavelength & References \\
\hline Carvedilol and hydrochlorothiazide & $241\left(\lambda_{\max }\right.$ of carvedilol) and 229.2 (isoabsorptive point) \\
Atenolol and ivabradine & $276\left(\lambda_{\max }\right.$ of atenolol) and 286.40 (isoabsorptive point) \\
Propranolol and flunarizine & $253\left(\lambda_{\max }\right.$ of flunarizine) and 272.8 (isoabsorptive point) \\
Prednisolone and 5-aminosalicylic acid & $302\left(\lambda_{\max }\right.$ of 5-ASA) and 283 (isoabsorptive point) \\
Naproxen and paracetamol & $257\left(\lambda_{\max }\right.$ of paracetamol) and 234 (isoabsorptive point) \\
Cefixime and moxifloxacin & $293.6\left(\lambda \lambda_{\max }\right.$ of moxifloxacin) and 276 (isoabsorptive point) \\
Difluprednate and gatifloxacin & $241\left(\lambda_{\max }\right.$ Difluprednate $)$ and 236 (isoabsorptive point) \\
\hline
\end{tabular}

Table 10: Absorptivity factor method application to following drugs in pharmaceutical dosage forms

\begin{tabular}{lll}
\hline Drug & $\begin{array}{l}\text { Wavelength used for } \\
\text { analysis of mixture }\end{array}$ & References \\
\hline $\begin{array}{l}\text { Salmeterol xinafoate and } \\
\text { fluticasone propionate }\end{array}$ & $227.8 \mathrm{~nm}$ & {$[50]$} \\
$\begin{array}{l}\text { Sodium cromoglicate and } \\
\text { fluorometholone }\end{array}$ & $241 \mathrm{~nm}$ & {$[51]$} \\
\hline
\end{tabular}

$C_{\mathrm{X}}=\left(\mathrm{Q}_{\mathrm{m}}-\mathrm{Q}_{\mathrm{y}}\right) \times \mathrm{A} /\left(\mathrm{Q}_{\mathrm{X}}-\mathrm{Q}_{\mathrm{Y}}\right) \times \mathrm{ax}_{1}$

$\mathrm{C}_{\mathrm{Y}}=\left(\mathrm{A} / \mathrm{ax}_{1}\right)-\mathrm{C}_{\mathrm{X}}$

$\mathrm{Qm}=\mathrm{A}_{2} / \mathrm{A}_{1}$

$A_{1}$ is absorbance of sample at isoabsorptive point, $A_{2}$ is absorbance of sample at $\lambda_{\max }$ of one of the two components ax1 and ax 2 represent absorptivities of $\mathrm{X}$ at $\lambda 1$ and $\lambda 2$ and ay 1 and ay 2 denote absorptivities of $Y$ at $\lambda_{y} 1$ and $\lambda_{x} 2$, respectively, $C X$ and $C Y$ are the concentrations of $X$ and $Y$, respectively.

\section{ABSORPTIVITY FACTOR METHOD}

This method is a modification of classical absorption method. For implementing this method of spectroscopic analysis following conditions must be fulfilled $[50,51]$

- This method is applicable to binary mixture

- There should be larger difference in between absorptivity of both drugs

- There should not be isoabsorptive point

In contrast to isoabsorptive point method, crossing of spectra do not occur at same concentration, however, it may occur at different drug concentrations. At such crossing point in absorptivity factor method, absorptivity is equal to the inverse ratio of concentrations used. The ratio found is known as absorptivity as absorptivity factor (F), and the crossing point is known as absorptivity factor point [50].

$A_{x}=a_{x} b c_{x}$ and $A_{y}=a_{y} b c_{y}$

At crossing point of equal absorptivity having different drug concentrations

$$
\begin{aligned}
& A_{x}=A_{y} \\
& a_{x} b c_{x}=a_{y} b_{y} \\
& a_{x} c_{x}=a_{y} c_{y} \\
& a_{x /} a_{y}=c_{y /} c_{x}=F \\
& a_{x /} a_{y}=F \\
& A_{m}=A_{x}+A_{y}=a_{x} b c_{x}+a_{y} b c_{y}
\end{aligned}
$$

Where $b=1$

$$
\begin{aligned}
& A_{m}=a_{x} c_{x}+a_{y} c_{y} \\
& a_{x}=F a_{y} \\
& A_{m}=F a_{y} c_{x}+a_{y} c_{y}=a_{y}\left(F c_{x}+c_{y}\right) \\
& \text { Similarly, } A_{m}=a_{x}\left(F c_{y}+c_{x}\right)
\end{aligned}
$$

Concentration of y drug can be determined using linear regression equation between its concentration and absorbance at its wavelength of maximum absorption where interference due to other drugs is null. Later from the concentration of $\mathrm{y}$ the concentration of $\mathrm{x}$ can be determined using following equation [4-35].

$$
\begin{aligned}
& A_{m}=a_{y}\left(F c_{x}+c_{y}\right)=a_{x}\left(F c_{y}+c_{x}\right) \\
& a_{y}\left(F c_{x}+c_{y}\right)=a_{x}\left(F c_{y}+c_{x}\right) \\
& c_{x}=\left[\left(F c_{x}+c_{y}\right)-c_{y}\right] / F
\end{aligned}
$$

Table 10 summarizes the applications of absorptivity factor method application to following drugs in pharmaceutical dosage forms.

\section{Absorption factor method}

Absorption factor method is another spectroscopic method applicable to the analysis of binary mixtures. In those cases where the overlapped spectra observed found, interferences at absorbance maxima of one component observed while no interference observed at absorbance maxima of another compound [51].

Consider a mixture of $\mathrm{x}$ and $\mathrm{y}$ having a wavelength of maxima at $\lambda_{\mathrm{x}}$ and $\lambda_{y}$. Y shows interference at $\lambda_{\mathrm{x}}$ but $\mathrm{x}$ do not shows interference at $\lambda_{\mathrm{y}}$. In this method different standard concentration of Y such as a, b, c, and d are scanned in the range of $200-400 \mathrm{~nm}$.

The average value of absorbance factor was calculated using the following equation:

$\left(\mathrm{A}_{\mathrm{Y} 1} \lambda_{\mathrm{Y} 1} / \mathrm{A}_{\mathrm{Y} 2} \lambda_{\mathrm{Y} 2}\right)_{\mathrm{a}}+\left(\mathrm{A}_{\mathrm{Y} 1} \lambda_{\mathrm{Y} 1} / \mathrm{A}_{\mathrm{Y} 2} \lambda_{\mathrm{Y} 2}\right)_{\mathrm{b}}+\left(\mathrm{A}_{\mathrm{Y} 1} \lambda_{\mathrm{Y} 1} / \mathrm{A}_{\mathrm{Y} 2} \lambda_{\mathrm{Y} 2}\right)_{\mathrm{c}}+\left(\mathrm{A}_{\mathrm{Y} 1} \lambda_{\mathrm{Y} 1} / \mathrm{A}_{\mathrm{Y} 2} \lambda_{\mathrm{Y} 2}\right)_{\mathrm{d}}$ $\left(\mathrm{A}_{\mathrm{Y} 1} \lambda_{\mathrm{Y} 1} / \mathrm{A}_{\mathrm{Y} 2} \lambda_{\mathrm{Y} 2}\right)_{\mathrm{avg}}$

$\left(\mathrm{A}_{\mathrm{Y} 1} \lambda_{\mathrm{Y} 1} / \mathrm{A}_{\mathrm{Y} 2} \lambda_{\mathrm{Y} 2}\right)_{\mathrm{avg}}$ is the average value of absorbance factor.

Since at $\lambda_{\mathrm{y}}$ only y shows absorbance at this wavelength concentration of $\mathrm{y}$ can be determined. From this concentration of $\mathrm{x}$ can be obtained using the following formula:

$\mathrm{A}_{\mathrm{x}} \lambda_{\mathrm{x}}=\mathrm{A}_{(\mathrm{X}+\mathrm{Y})} \lambda_{1}-\mathrm{A}_{(\mathrm{X}+\mathrm{Y})} \lambda_{2}^{*}\left(\mathrm{~A}_{\mathrm{Y} 1} \lambda_{\mathrm{Y} 1} / \mathrm{A}_{\mathrm{Y} 2} \lambda_{\mathrm{Y} 2}\right)_{\mathrm{avg}}$

The above equation is foundation of absorption factor method.

Table 11 summarizes pharmaceutical applications of absorption factor method to binary mixtures of drugs in combined dosage form.

\section{MULTIVARIATE CHEMOMETRIC METHOD}

It is the processing of analytical data by mathematical techniques. It can also be defined as multiple measurements on the same sample due to 
Table 11: Pharmaceutical applications of absorption factor method to binary mixtures of drugs in combined dosage form

\begin{tabular}{lll}
\hline Drug & $\begin{array}{l}\text { Wavelength 1 (both drugs shows } \\
\text { absorbance) (nm) }\end{array}$ & $\begin{array}{l}\text { Wavelength 2 (one drugs shows } \\
\text { absorbance) (nm) }\end{array}$ \\
\hline Sodium cromoglicate and fluorometholone & 241 & 325 \\
Ramipril and olmesartan medoxomil & 210 & 256 \\
Perindopril erbumine and amlodipine besylate & 215 & 237 \\
\hline
\end{tabular}

this correlation of physical properties to analytical data can be done. According to chemometric methods, it is often better to measure many nonselective signal and later combining them in a multivariate model where multiple variable considered simultaneously [53].

Multivariate methods include:

1. Multiple linear regression (MLR) methods

a. Classical least squares or (K-matrix)

b. Inverse least squares or (P-matrix)

2. Factor-based methods

a. Principal component regression (PCR)

b. Partial least squares (PLS).

In the case of spectroscopy, if the absorbance spectra of a number of samples of known composition are measured, all these spectra are assembled into one matrix called the absorbance matrix. While in concentration matrix, all concentration values for the components of the sample are assembled.

In general, MLR and PCR techniques employ data organized as matrices of column vectors, while PLS technique employs data organized as matrices of row vectors [53].

The data of matrices are organized into pairs; each absorbance matrix is paired with its corresponding concentration matrix. The pair of matrices comprises a data set. Data sets have different names depending on their origin and purpose [53].

Training set is a data set containing measurements on a set of known samples. It is used to develop the calibration which is applied to predict the concentrations of unknown samples. Training set should contain all expected components, span the concentration ranges of interest and contain mutually independent samples [53].

Validation set is an additional dataset containing independent measurements on samples that are independent from the samples used to create the training set. Validation set is used to test the validity of the calibration developed with the training set. The developed calibration is used to predict the concentrations of the components in the validation samples. Then, these predicted concentrations are compared to the actual concentrations [53].

The absorbance matrix containing the unknown(s) spectra together with the corresponding result matrix containing the predicted concentrations comprise an unknown set.

Table 12 summarizes pharmaceutical applications of multivariate chemometric method to binary mixtures of drugs in combined dosage form.

\section{Isosbestic point method}

This technique can be used only if the spectra of the same concentration of the two studied drugs cross at a point called isosbestic or isoabsorptivity point. At the isosbestic point, both drugs have equal absorptivities, and their mixture acts as a single component and gives the same absorbance as pure drug. The absorbance value at the isosbestic point (Aiso) was determined, and the total concentration of both drugs was calculated. Since the concentration of one of them in this mixture can be measured using other spectroscopic method (DS), the concentration of the other could be calculated by subtraction.
Table 12: Pharmaceutical applications of multivariate chemometric method to binary mixtures of drugs in combined dosage form

\begin{tabular}{lll}
\hline Drug & $\begin{array}{l}\text { Multivariate } \\
\text { chemometric } \\
\text { method }\end{array}$ & References \\
\hline $\begin{array}{l}\text { Levodopa and benserazide } \\
\text { Cypermethrin and tetramethrin }\end{array}$ & PLS & {$[54]$} \\
$\begin{array}{l}\text { Moexipril and } \\
\text { hydrochlorothiazide }\end{array}$ & PLS, PCR & {$[55]$} \\
\hline
\end{tabular}

A linear correlation was obtained between the absorbance values and the corresponding drug concentrations. Consider you have a mixture of two drugs $x$ and $y$. The absorbance of each drug can be calculated at any wavelength $(\lambda)$ from the equation

$\mathrm{A}=\mathrm{abc}$

Therefore, for drug $\mathrm{x}: \mathrm{A}_{\mathrm{x}}=\mathrm{a}_{\mathrm{x}} \mathrm{b} \mathrm{C}_{\mathrm{x}}$ and

For drug $\mathrm{y}: \mathrm{A}_{\mathrm{y}}=\mathrm{a}_{\mathrm{y}} \mathrm{bC}$

Where $\mathrm{a}_{\mathrm{x}}$ and $\mathrm{a}_{\mathrm{y}}$ are the absorbances of $\mathrm{x}$ and $\mathrm{y}$, respectively; $\mathrm{Cx}$ and Cy are the concentrations of $\mathrm{x}$ and $\mathrm{y}$, respectively; and are the absorbtivities when the path length (b) is $1 \mathrm{~cm}$, and concentration is $1 \mathrm{~g} / 100 \mathrm{~mL}$ for $\mathrm{x}$ and $\mathrm{y}$, respectively.

If $\mathrm{C}_{\mathrm{x}}=\mathrm{C}_{\mathrm{y}^{\prime}}$ and $\mathrm{a}_{\mathrm{x}}=\mathrm{a}_{\mathrm{y}^{\prime}}$ this $\lambda$ is called the isosbestic point, and

At this $\lambda A_{x}=A_{y}$

For a mixture of both drugs, the absorbance at this $\lambda$ can be calculated from the equation

$$
\begin{aligned}
& A=a_{x} C x+a_{y} C y \\
& A=a_{x}(C x+C y)
\end{aligned}
$$

Where $\mathrm{A}$ is the absorbance of their mixture at isosbestic point and is the concentrations of drugs $\mathrm{x}$ and $\mathrm{y}$ in the mixture, respectively, and $\mathrm{C}_{\mathrm{TM}}$ is the concentration of their mixture.

Therefore, we can conclude that

$A=a_{x} C_{T M}$

Thus, having the total concentration of both drugs, if the concentration of one of them can be determined separately by any other method, the concentration of the second drug can be calculated by subtraction [57].

This method applied for the analysis of the ternary mixture of chloramphenicol, dexamethasone sodium phosphate (DXM) and tetryzoline hydrochloride in eye drops [58].

Advantages of UV spectroscopy over other analytical techniques (Table 13)

Furthermore, UV spectrophotometer is a highly simple instrument which makes it easier to couple with other analytical instrument such 
Table 13: Advantages of ultraviolet spectroscopy over other analytical techniques

\begin{tabular}{llll}
\hline Parameter & Ultraviolet spectroscopy & Chromatography & Thermal technique \\
\hline Instrumentation & Easy & Complex & Complex \\
Interference in analysis & Less & High (instrumental, physicochemical) & High (instrumental, physicochemical) \\
\hline
\end{tabular}

as RP-HPLC [59]. Apart from this one UV spectrophotometric method had been conveniently adopted to develop a new better analytical method [60]. Such method transfer and instrument compatibility are facilitated with UV spectroscopy only.

\section{CONCLUSION}

Number of multicomponent formulations, biopharmaceutical products and samples of complex matrix and biological origin are present in the market for which different analytical techniques can be applied including spectrophotometry, chromatography, and electrophoresis but UV spectrophotometric methods for determination of drugs are easier, cheaper, simple, and rapid. Since most analytes of interest are accompanied in their dosage forms by other compounds absorbing in the same spectral region, classical UV spectral measurements could not be used for their determination. Hence, all of the above methods can be used according to their nature. Among the UV spectroscopic techniques depending on the nature of analysis particular method can be selected. Method such as simultaneous and derivative spectroscopy can be used to analyze both binary and tertiary mixture, where such as, for resolving closely absorbing peaks derivatives spectroscopy advantageous while simultaneous spectroscopy is better in terms of its simplicity. Furthermore, variants based on derivative spectroscopy such as ratio derivative spectroscopy, successive ratio derivative spectroscopy offer more advantages in terms of eliminating chemical interferences. High selectivity and specificity can be obtained for analyzing equimolar solutions of analyte in UV active matrix using difference spectroscopy, can be applied to bi single drug as well as binary mixture analysis. Depending on the absorbance points of drugs in binary mixture absorption factor method, absorptivity factor method and q-absorbance ratio methods are used. Apart from that UV visible spectroscopy offer more advantages in terms of robustness, less troubleshooting, physicochemical interferences as compared to other sophisticated instruments such as chromatographic and thermal techniques. Hence, UV spectrophotometry is the best option for an analyst for analysis in the pharmaceutical industry.

\section{REFERENCES}

1. Pavia D, Lampman G, Krix G. Introduction to Spectroscopy. Bloomington, IN: Indiana University; 2001

2. Shetty PR, Patil DD. Applications of simultaneous equation method and derivative method for the determination of rabeprazole sodium and levosulpiride in pharmaceutical dosage form and dissolution samples. J Assoc Arab Univ Basic Appl Sci 2014;15:53-60.

3. Patel PB. Development and validation of a method for simultaneous estimation of ofloxacin and ornidazole in different dissolution media. Pharm Methods 2012;3:102-5

4. Pant M, Dadare K, Khatri NC. Application of UV spectrophotometric methods for simultaneous estimation of norfloxacin and tinidazole in bulk and tablet dosage forms. Pharm Chem 2012;4:1041-6.

5. Sharma R, Pathodiya G, Mishra GP, Sainy J. Spectrophotometric methods for simultaneous estimation of paracetamol and diclofenac sodium in combined dosage form by application of hydrotropic solubilization. J Pharm Sci Res 2010;2:821-6.

6. Donovan J. Ultraviolet deiiference spectroscopy- new techniques and application. Conform Transitions 1972;18:498-525.

7. Anandakumar K, Buddi N. Development of difference spectroscopic method for the estimation of tapentadol hydrochloride in bulk and in formulation. Int J PharmTech 2012;4:1586-90.

8. Nikolaidis A, Moschakis T. Studying the denaturation of bovine serum albumin by a novel approach of difference-UV analysis. Food Chem 2016;215:1-24.

9. Prabu SL, Shanmugarathinam A. Development of difference spectrophotometric method for the estimation of leflunomide in tablet dosage form. Chem Ind Chem Eng Q 2012;18:407-10.

10. Rajput SJ, Raj HA. Assay of tegaserod maleate by difference spectroscopy. Indian J Pharm Sci 2007;69:114-5.

11. Affleck RP, Spitznagel TM. Application of difference spectroscopy to biopharmaceutical formulation development. Am Lab 2017;1:6-9.

12. Talsky G. Derivative Spectrophotometry Low and Higher Order. $1^{\text {st }}$ ed. New York: VCH; 1994.

13. Haver TC. Analytical concepts potential clinical applications of derivative and wavelength-modulation spectrometry. Anal Concepts 1979;25:1548-53.

14. Karpinska J. Analytical application of derivative spectrophotometry. In: Macro to Nano Spectroscopy. Poland: Bialystok; 2012. p. 254-68.

15. Ojeda CB, Rojas FS. Recent applications in derivative ultraviolet/visible absorption spectrophotometry: 2009-2011. A review. Microchem J 2013;106:1-16.

16. Ojeda CB, Rojas FS. Recent developments in derivative ultraviolet/ visible absorption spectrophotometry. Anal Chim Acta 2004;518:1-24

17. Rojas FS, Ojeda CB. Recent development in derivative ultraviolet/ visible absorption spectrophotometry: 2004-2008. A review. Anal Chim Acta 2009;635:22-44.

18. Tabbouche OS, Soukkariyyeh I. First-order derivative ultraviolet spectrophotometry of imipenem E cilastatin formulations. J Taibah Univ Med Sci 2014;9:178-81.

19. Rosa AM, Sversut A, Alca IC. Simultaneous determination of gatifloxacin and prednisolone acetate in ophthalmic formulation using first-order UV derivative spectroscopy. Aarab J Chem 2014;6:1-8.

20. Swapnil AS, Sachin SP, Rajan VR. First order derivative spectroscopy method in combined dosage form. Chem Sin 2013;4:43-8.

21. Rajput S, Raj H. Simultaneous estimation of ezetimibe and lovastatin by derivative spectroscopy. Int J PharmTech Res 2009;1:894-9.

22. Attimarad M, Al-dhubiab BE, Alhaider IA, Nair AB. Imultaneous determination of moxifloxacin and cefixime by first and ratio first derivative ultraviolet spectrophotometry. Chem Cent J 2012;20:1-7.

23. Patel B, Jadav A, Solanki H, Parmar S, Parmar V, Captain A, et al. Development and validation of derivative spectroscopic method for the simultaneous estimation of rosuvastatin calcium and fenofibrate in tablet. Int J Pharm Res Rev 2013;2:1-6.

24. Patel P, Vaghela V, Rathi S, Rajgor N, Bhaskar V. Derivative spectrophotometry method for simultaneous estimation of rupatadine and montelukast in their combined dosage form. J Young Pharm 2009; $1: 354-8$.

25. Abdel-hay MH, Gazy AA, Hassan EM, Belal TS. Derivative and derivative ratio spectrophotometric analysis of antihypertensive ternary mixture of amiloride hydrochloride, hydrochlorothiazide and timolol maleate. J Chin Chem Soc 2008;55:971-8.

26. Dave HN, Mashru RC, Thakkar AR. Simultaneous determination of salbutamol sulphate, bromhexine hydrochloride and etofylline in pharmaceutical formulations with the use of four rapid derivative spectrophotometric methods. Anal Chim Acta 2007;597:113-20.

27. El-zaher AA, Hassib ST, El-zaher AA, Fouad MA. Validated stabilityindicating derivative and derivative ratio methods for the determination of some drugs used to alleviate respiratory tract disorders and their degredent. Drug Test Anal 2011;3:1-5.

28. Petrov V, Antonov L, Ehara H. Step by step filter based program for calculations of highly informative derivative curves. Comput Chem 2000;24:561-9.

29. Vega-montoto L, Brown CD, Ontoto LV. Derivative preprocessing and optimal corrections for baseline drift in multivariate calibration derivative preprocessing and optimal corrections for. Appl Spectrosc 2014;54:1055-68.

30. Hoang VD, Thi D, Ly H, Tho NH, Minh H, Nguyen T, et al. UV spectrophotometric simultaneous determination of paracetamol and ibuprofen in combined tablets by derivative and wavelet transforms. Sci World J 2014;2014:1-13.

31. Salinas F, Mansilla AE. A new spectrophotometric method for quantitative multicomponent analysis resolution of mixtures of salicylic and salicyluric acids. Talanta 1990;37:347-51

32. Sabnis SS, Dhavale ND, Jadhav VY, Gandhi SV. Spectrophotometric simultaneous determination of rabeprazole sodium and itopride 
hydrochloride in capsule dosage form. Indian $\mathrm{J}$ Pharm Sci 2008;69:849-52.

33. Hajian R, Shams N, Kaedi I, Club YR. Application of ratio derivative spectrophotometry for simultaneous determination of naphazoline and antazoline in eye drops. E J Chem 2010;7:1530-8.

34. Fayez YM, Elghobashy MR, Goda ZM, Shehata MA. Comparative study on four spectrophotometric methods manipulating ratio spectra for the simultaneous determination of binary mixture of diflucortolone valerate and isoconazole nitrate. Bull Fac Pharm 2016;54:2-9.

35. Pravinbhai P, Patel PB. Development and validation of ratio-derivative spectrophotometric method for simultaneous estimation of gabapentin, methylcobalamin and alpha lipoic acid in tablet formulation. J Pharm Res 2013;6:609-14.

36. Afkami A, Bahram M. Successive ratio-derivative spectra as a new spectrophotometric method for the analysis of ternary mixtures for the analysis of ternary mixtures. Spectrochim Acta Part A 2005;61:869-77.

37. Abdelwahab NS. Spectrophotometric methods for simultaneous determination of carvedilol and hydrochlorothiazide in combined dosage form. Arab J Chem 2016;9:S355-60.

38. Patil PA, Raj HA, Sonara GB. Q-absorbance ratio spectrophotometric method for simultaneous determination of atenolol and ivabradine hydrochloride in synthetic mixture. Pharm Biol 2016;3:224-30.

39. Patil A, Surana S. Q-absorbance and multicomponent UV spectrophotometric methods for simultaneous estimation of propranolol. Scholars research library. Pharm Chem 2016;3:404-8.

40. Singh G, Kumar D, Sharma D, Singh M. Q-absorbance ratio spectrophotometric method for the simultaneous estimation of prednisolone and 5-amino salicylic acid in tablet dosage form. J Appl Pharm Sci 2012;2:222-6.

41. Patel A, Firke SD, Bari SB, Ranoliya JR. Development and validation of UV-spectrophotometric method for simultaneous estimation of naproxen and paracetamol by Q-absorbance ratio method. Int J Pharm Res Allied Sci 2014;3:57-63.

42. Pandey G, Mishra B. A new analytical Q-absorbance ratio method development and validation for simultaneous estimation of lamivudine and isoniazid. ISRN Spectrosc 2013;2013:1-5.

43. Patel P, Patel D, Desai S, Meshram D. Development and validation of analytical methods for simultaneous estimation of difluprednate and gatifloxacin in ophthalmic emulsion by Uv-visible spectroscopy. Int J Pharm Sci 2014;3:1-10.

44. Samir A, Salem H, Abdelkawy M. New developed spectrophotometric method for simultaneous determination of salmeterol xinafoate and fluticasone propionate in bulk powder and seritide òdiskus inhalation. Bull Fac Pharm Cairo Univ 2012;50:121-6.

45. Saleh SS. A comparative study of validated spectrophotometric and TLC-spectrodensitometric methods for the determination of sodium cromoglicate and fluorometholone in ophthalmic solution. Saudi Pharm J 2013;21:411-21.

46. Sharma R, Mehata K. Simultaneous spectrophotometric estimation of tenofovir disoproxil fumarate and lamivudine in three component tablet formulation containing efavirenz. Indian J Pharm Sci 2010;74:527-30.
47. Galande V, Baheti K, Indraksha S, Dehgan M. Estimation of amlodipine besylate, valsartan and hydrochlorothiazide in bulk mixture and tablet by UV spectrophotometry. Indian J Pharm Sci 2012;74:18-23.

48. Wankhede SB, Raka KC, Wadkar SB, Chitlange SS. Spectrophotometric and HPLC methods for simultaneous estimation of amlodipine besilate, losartan potassium and hydrochlorothiazide in tablets. Indian J Pharm Sci 2010;72:136-40.

49. Aneja G, Dave U, Vadodaria, K. Simultaneous estimation of piperine, quercetin, and curcumin in a mixture using UV-visible spectrophotometer and method validation. Int J Ther Appl 2012;8:14-7.

50. Sujana K, Abbulu K, Souri OB, Archana B, Sindu M, Rani GS, et al. Difference spectrophotometric methods for pioglitazone hydrochloride and metformin hydrochloride. J Pharm Sci Res 2011;3:1122-6.

51. Rote AR, Kumbhoje PA, Bhambar RS. UV-visible spectrophotometric simultaneous estimation of paracetamol and nabumetone by AUC method in combined tablet dosage form. Pharm Methods 2012;3:40-3.

52. Akhtar J, Prajapati J, Elhassan GO, Mujahid M. Development and validation of absorbance ratio method for simultaneous estimation of lornoxicam and eperisone in their synthetic mixture. Indo Glo J Pharm Sci 2015;5:225-32

53. Hassaninejad-darzi SK, Samadi-maybodi A, Mohsen S. UV-vis spectrophotometry and multivariate calibration method for simultaneous determination of theophylline, montelukast and loratadine in tablet preparations and spiked human plasma. Iran J Pharm Res 2016;15:379-91.

54. Coello J, Maspoch S, Simultaneous kinetic spectrophotometric determination of levodopa and beserazide by bi-and three-way partial least squares calibration. Talanta 2000;53:627-37.

55. Tawakkol S, Farouk M, Delaziz M, Hemdan A, Shehata M. Comparative study between univariate spectrophotometry and multivariate calibration as analytical tools for simultaneous quantitation of moexipril and hydrochlorthiazide. Spectrochim Acta Part A Mol Biomol Spectrosc 2014;133:300-6.

56. Erram SV, Tipnis HP. Simple spectrometric analysis of propranolol hydrochloride and hydrochlorothiazide from combined pharmaceutical dosages. Indian Drugs 1994;31:65-8.

57. Lotfy HM, Saleh SS, Hassan NY, Salem H. A comparative study of novel spectrophotometric methods based on isosbestic points; Application on a pharmaceutical ternary mixture. Spectrochim Acta A Mol Biomol Spectrosc 2014;126:112-21

58. Niazi A, Mohammad G, Orthogonal signal correction partial least squares method for simultaneous spectrophotometric determination of cypermethrin and tetramethrin. Spectrochim Acta Part A Mol Biomol Spectrosc 2008;69:1165-9.

59. Swathi P, Vidyadhara S, Sasidhar RL, Chakravarthi KK. Method development and validation for the estimation of entecavir in bulk and pharmaceutical dosage forms by RP-HPLC. Int J Curr Pharm Res 2017;9:107-11.

60. Pournima P, Vaishali B, Harinath M, Sachin P. Spectrophotometric method for simultaneous determination of olmesartan medoxomil and amlodipine besylate from tablet dosage form. Int J Curr Pharm Res 2011;3:7479. 